\title{
Dynamics of the Typhoon Haitang Related High Ozone Episode over Hong Kong
}

\author{
Xiaolin Wei, ${ }^{1}$ Ka-se Lam, ${ }^{2}$ Chunyan Cao, ${ }^{1} \mathrm{Hui} \mathrm{Li}^{1},{ }^{1}$ and Jiajia $\mathrm{He}^{1}$ \\ ${ }^{1}$ Shenzhen Key Laboratory of Severe Weather in South China, Meteorological Bureau of Shenzhen Municipality, \\ Shenzhen 518040, China \\ ${ }^{2}$ Department of Civil and Environmental Engineering, The Hong Kong Polytechnic University, Hung Hom, Hong Kong \\ Correspondence should be addressed to Xiaolin Wei; xiaolinwei189@hotmail.com
}

Received 8 October 2015; Revised 22 November 2015; Accepted 1 December 2015

Academic Editor: Xiao-Ming Hu

Copyright (C) 2016 Xiaolin Wei et al. This is an open access article distributed under the Creative Commons Attribution License, which permits unrestricted use, distribution, and reproduction in any medium, provided the original work is properly cited.

\begin{abstract}
It has been previously established that photochemical smog occurring in the Pearl River Delta Region (PRD) was associated with stagnant meteorological conditions. However, the photochemical smog (17 July to 20 July 2005) induced by typhoon Haitang was associated with moderate wind speed and nonstagnant meteorological conditions. The dynamic process of this ozone episode was studied using an integrated numerical model, that is, a mesoscale meteorological model and Community Multiscale Air Quality (CMAQ) model. Model performance has been evaluated using both ground-based meteorological and air quality observations. Analysis of simulated wind fields and ozone budget has been performed. This dynamic process is summarized into three physical factors. First, the westerly wind placed Hong Kong directly downwind of the PRD emissions. Second, the convergence of wind flow stimulated a vertical local circulation near the surface layer. This recirculation allowed primary and secondary pollutants to accumulate. Third, the conditions of high air temperature and low humidity resulted in active photochemical reactions. These combined effects resulted in the formation of high ozone in this episode.
\end{abstract}

\section{Introduction}

Hong Kong is a subtropical coastal mega city located in the Pearl River Delta (PRD) region, which is one of the most rapidly urbanized and industrialized regions in China. In the past two decades, air pollutant emissions from motor vehicles, power plants, industry, and infrastructure construction have been increasing due to rapid economic development. This has directly resulted in the deterioration of air quality as well as degradation in visibility.

High levels of ozone are occasionally found in various districts of Hong Kong (http://www.epd.gov.hk/epd/english/ environmentinhk/air/studyrpts/files/final_rept.pdf). Many studies have reported that synoptic-scale flow patterns and meso/local weather phenomenon have strong effects on the development of photochemical ozone episodes in the PRD region [1-3]. Weather patterns related to winter monsoon and tropical cyclones are found to be conducive to the occurrence of smog $[4,5]$. Lee et al. [6] studied Hong Kong surface ozone episodes in the summer months between 1994 and 1999, while tropical cyclones dominated circulation patterns in the PRD and South/Central China regions. They concluded that summer ozone episodes in Hong Kong are related to the tropical cyclone path. By inspecting weather charts, Wang and Kwok [7] also found out that severe and prolonged pollution episodes were induced by a quasistationary tropical cyclone in the East China Sea that caused air subsidence and stagnation over the PRD. Huang et al. [8] also similarly concluded that the synoptic patterns associated with tropical cyclones originating in the Western Pacific Ocean and the South China Sea were the most optimal weather conditions for the formation of ozone episodes in Hong Kong. Using aerosol observations, Wu et al. [9] showed that an extremely low visibility event over the PRD region in November 2003 was related to typhoon Melor. The presence of tropical cyclones caused a change 
in meteorological conditions and thus influenced local and regional haze [10-12].

On a smaller scale, Wang et al. [13] discovered that recirculation of "aged" urban air was another possible mechanism for high surface ozone episodes in Hong Kong. Hu and Xue [14] studied how sea breeze at nighttime significantly influenced the planetary boundary layer characteristics over coastal area. Ding et al. [15] showed how local wind fields, such as land-sea breeze circulation in coastal areas, influenced the transport of oxidant precursors, the residence time, and reentry of photochemical compounds. Lasry et al. [16] showed how the combination of sea and lake breezes with emissions of reactive volatile organic compounds (VOCs) can generate local intense ozone peaks.

The worst air quality in Hong Kong is believed to occur in presence of subsidence of a tropical cyclone, wherein there is abundance of solar radiation, low humidity, light wind, and weak dispersion [17]. Tropical cyclones produce a strong descent motion in the lower troposphere over the peripheral area, resulting in a relatively weak surface wind speed and low planetary boundary layer (PBL) in PRD. As a result, the strong subsidence confines the air pollutants into a very shallow layer, while the weak horizontal wind usually keeps air pollutants inside the source region, producing air quality problems such as photochemical smog and poor visibility.

Whereas previous studies have established the fact that the presence of a tropical cyclone on the western Pacific Ocean could induce poor air quality in the PRD, the driving mechanism may not be unique. A tropical cyclone is a moving system with a continuous change in location and intensity. These dynamics are expected to modulate atmospheric dispersion in the PRD. In this paper, we will reveal another mechanism for the ozone episodes under the tropical cyclone circulation. A case study was carried out for a regional ozone episode recorded in Hong Kong between 17 July and 20 July, 2005, when typhoon Haitang was moving across Taiwan. A numerical air quality simulation was performed using an integrated air quality modeling system consisting of MM5 3.7, CMAQ 4.6 [18-20], and Sparse Matrix Operator Kernel Emissions (SMOKE) model system. Our aim was to elucidate the evolution of typhoon Haitang together with the change in air quality. We sought to better understand the mechanism of the outer band flow of tropical cyclones and its relationship with poor air quality over the PRD.

\section{Characterization of Typhoon Haitang Related Ozone Episode}

2.1. Meteorological Characteristics. During the period from 17 July to 20 July 2005, a regional ozone episode was recorded at Hong Kong. At the same time, a mesoscale synoptic system, typhoon Haitang, was located at southeast of Taiwan. The locations of Haitang during this period are shown in Figures 1(a)-1(d). On 16 July, before the high ozone episode was formed, typhoon Haitang was located at $20.7^{\circ} \mathrm{N}, 127.7^{\circ} \mathrm{E}$ (about $800 \mathrm{~km}$ southeast of Taiwan). On $17 \mathrm{July}$, Haitang moved in a northwest direction towards Taiwan, where its outer band flow began to influence the PRD region and eventually landed in Taiwan on 18 July. Over the ensuing day, Haitang moved across the Taiwan straits and landed on Fujian Province of China on 20 July. The track of Haitang moved in a counterclockwise direction relative to Hong Kong. Thus, the location of the eye of Haitang had moved from an east to northeast direction over Hong Kong.

To gain insight into the relationship between high surface ozone $\left(\mathrm{O}_{3}\right)$ and typhoon Haitang, the observed meteorological parameters, including wind, relative humidity, and visibility (observed at HKO meteorological station, location shown in Figure 1(e)), with ozone concentration recorded at three air quality stations (locations shown in Figure 1(e)) during the month of July are shown in Figure 2. According to the weather report by the Hong Kong observatory, sunny weather first started on 10 July 2005 when a ridge of high pressure was established over the coast of south China. Sunny and hot weather persisted over the ensuing ten days. It became very hot locally from 17 July to 20 July, when Haitang was present over the western North Pacific. The intensely heated air in inland Guangdong moved over Hong Kong as it was entrained by the circulation of typhoon Haitang, bringing the local temperature to a maximum of $35.4^{\circ} \mathrm{C}$ on 19 July, the second highest temperature on record for July (http://www .hko.gov.hk/wxinfo/pastwx/mws200507.htm). Under the impact, high concentrations (>100 ppb) of $\mathrm{O}_{3}$ were observed at air monitoring stations in Hong Kong for four consecutive days from 17 July to 20 July, with maximum 1 h $\mathrm{O}_{3}$ concentration reaching $180 \mathrm{ppb}$ and visibility decreasing to $0.5 \mathrm{~km}$.

It is interesting to see in Figure 2 that when the ozone episode happened, the corresponding wind speed was relatively higher than any other days in July (except for the last three days, when an outer rain band associated with tropical storm Washi formed over the northern part of the South China Sea brought squally, heavy showers to Hong Kong; this information can be found at http://www.weather.gov.hk/ wxinfo/pastwx/mws200507.htm). From 17 July to 20 July, wind speeds averaged approximately $5 \mathrm{~m} \mathrm{~s}^{-1}$, with an associated westerly wind direction, which showed a noticeably larger recorded wind speed for this typhoon related ozone episode than any other typhoons reported in previous studies. One example for comparison is the tropical cyclone Melor [17], where surface wind in the PRD region was less than $1.5 \mathrm{~m} \mathrm{~s}^{-1}$.

Previous studies on typhoon related air pollution episodes have shown that subsiding air over the outer band of typhoon induced temperature rise and drying above the top of the boundary layer, resulting in temperature inversion and very stagnant conditions. However, in this case, the vertical structures of temperature and wind, as shown in Figure 3, do not show similar characteristics. Although there was a significant increase in temperature aloft (on 18 July to 20 July), there was no significant temperature inversion, with the wind speed much higher than on nonepisode days. Comparing the days between 18 July and 20 July (ozone episode) with other days between 1 July and 28 July (days without high ozone concentrations), the most significant difference occurred within the boundary layer (as simulated by MM5 model, the planetary boundary height showed 


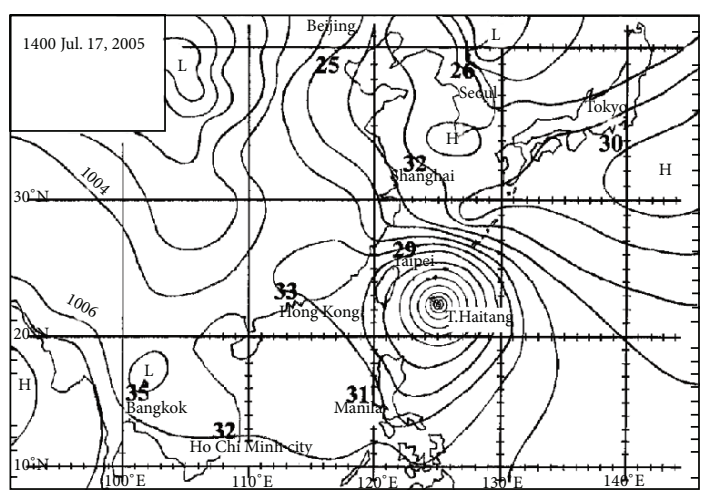

(a)

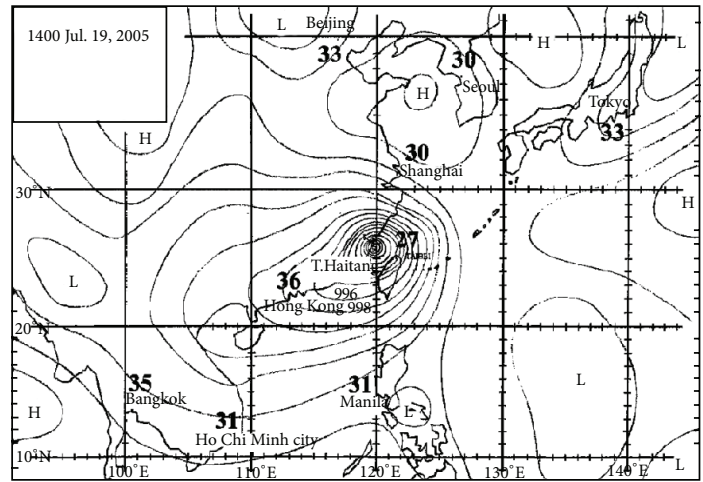

(c)

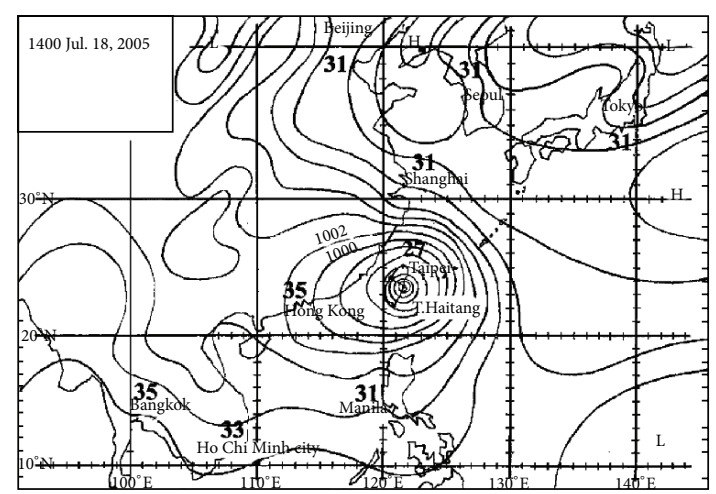

(b)

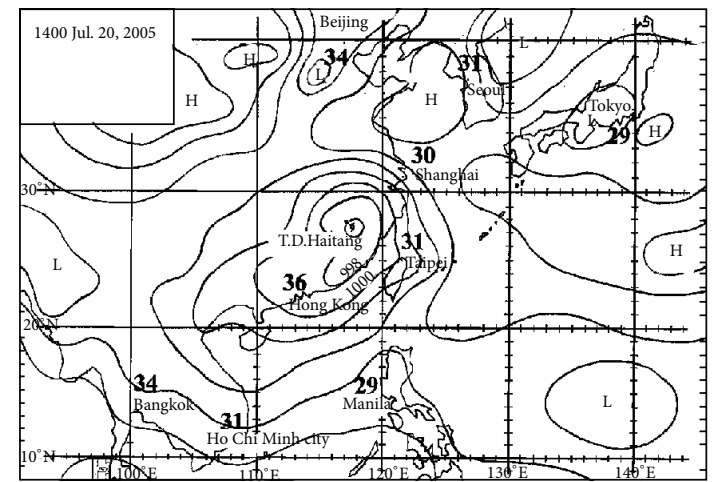

(d)

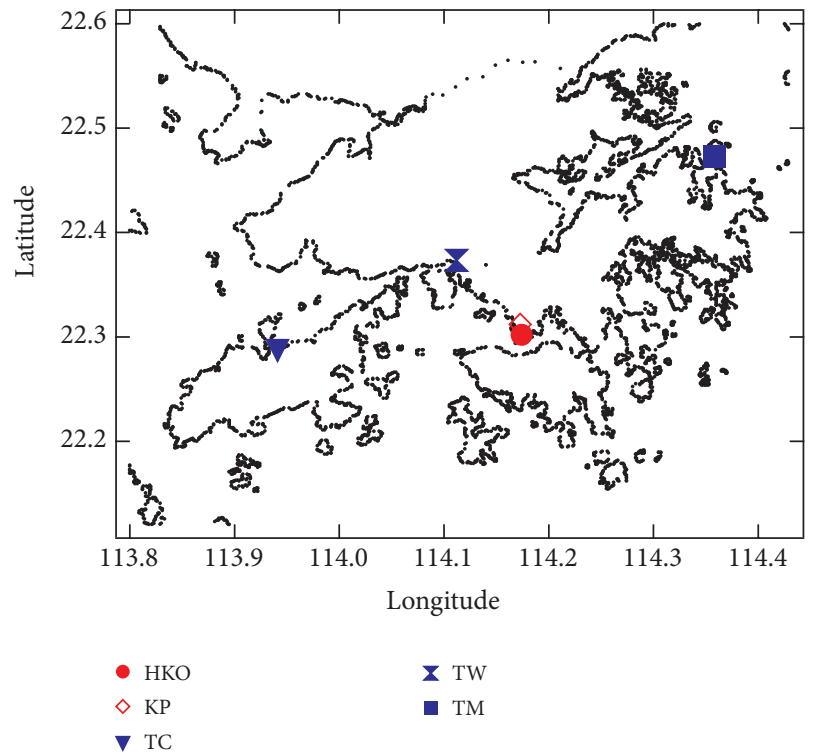

(e)

Figure 1: Weather charts of Hong Kong at 1400 LST from (a) 17 July to (d) 20 July, 2005; the contour shows the sea surface pressure, unit: $\mathrm{hPa}$. Locations of meteorological and air quality stations in Hong Kong are shown in (e) (location of Hong Kong is indicated as characters on weather charts).

regular diurnal variation of rapid increasing in the morning, reached the peak of about 1000 to 1200 meters at about 1400 to 1600 o'clock, and then decreased in the afternoon during the ozone episode days). Warming occurred throughout the boundary layer during the 3 episode days. Temperature was higher than normal by more than $3^{\circ} \mathrm{C}$ from ground up to 1000 meters. The relative humidity was low at $60 \%$ between 700 and 900 meters aloft. Westerly wind prevailed throughout the boundary layer. Figure 3 shows that during the ozone episode the $\mathrm{PRD}$ region was dominated by 


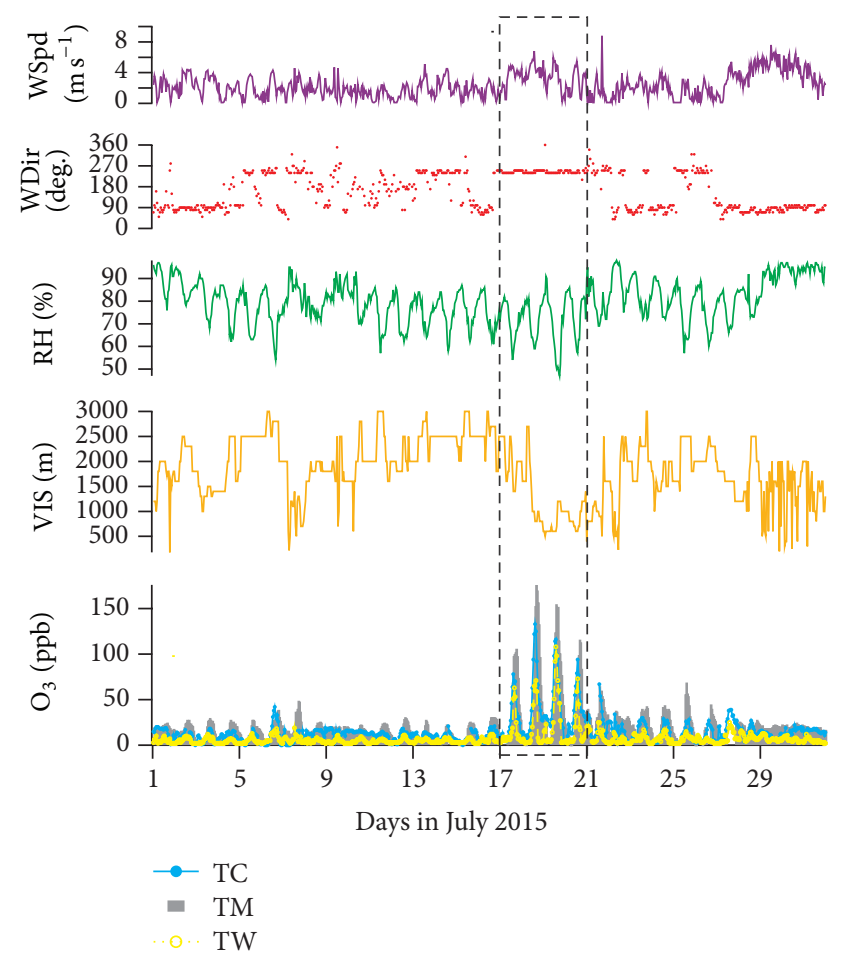

FIGURE 2: Hong Kong meteorology and ozone in July 2005. Starting from the top are wind speed, wind direction, relative humidity, and visibility observed at the Hong Kong Observatory (HKO). The bottom chart shows ozone concentrations recorded at three air quality stations: Tung Chung (TC), Tap Mun (TM), and Tsuen Wan (TW). The dashed rectangle is demarcating the ozone episode days from nonepisode days.

a relatively dry and strong northwesterly wind flow in the upper boundary layer while the ground level had more moisture with moderate westerly wind $\left(\sim 5 \mathrm{~m} \mathrm{~s}^{-1}\right.$ for 18 to 20 July). The absence of an inversion layer implies a different impact mechanism of the tropical cyclone on photochemical smog in the PRD region and justifies further studies.

2.2. Characteristics of Downwind $\mathrm{O}_{3}, \mathrm{CO}, \mathrm{NO}_{x}$, and $\mathrm{SO}_{2}$ during the Episode. The air pollutant concentrations observed at the downwind air monitoring station, Tap Mun (TM), are shown in Figure 4. Considering Hong Kong was under northwesterly and westerly wind within the PBL, the TM station, which is located to the east of Hong Kong, was situated in a downwind location. High surface ozone concentrations exceeding $100 \mathrm{ppb}$ were observed in the afternoon from 17 to 20 July. On both 18 July and 19 July, the surface ozone concentrations exceeded $150 \mathrm{ppb}$. During the episode, the diurnal variation pattern of $\mathrm{CO}, \mathrm{SO}_{2}$, and $\mathrm{NO}_{x}$ was quite similar to that of ozone. The substantial increase and rapid fluctuations of air pollutants in the TM station can be interpreted as the impact of both regional and local emission sources from urban areas of the PRD as well as Hong Kong.

In the following sections, the transport and chemical transformation of this episode are studied using an air modeling system.

\section{Modeling System}

An air quality modeling system was set up to simulate air pollutant concentrations during this episode. A large one-way domain was established. The horizontal resolution was $36 \mathrm{~km}$ and centered at $\left(34.0^{\circ} \mathrm{N}, 110.0^{\circ} \mathrm{E}\right)$. The numbers of the grid cells along the north-south and east-west directions were $111 \times 178$. The meteorological numerical simulation was made using the fifth-generation Pennsylvania State University-National Center for Atmospheric Research (NCAR) Mesoscale Model MM5, version 3.7. MM5 then provided meteorological fields for inputs into the US Environmental Protection Agency (EPA) air quality model MODELS-3/CMAQ (Community Multiscale Air quality) [21] as well as emission preparation. CMAQ was then run for air quality simulation. This modeling domain encompassed a large area of East China, which consists of several industrial centers, such as Beijing, Yangtze River Delta region, and the $\mathrm{PRD}$ region. The modeling system was configured using 43 vertical layers in the $\sigma$ coordinate system with its top fixed at $100 \mathrm{hPa}$. The Blackadar PBL scheme, which is suitable for high-resolution simulation, was applied. A mix phase process was selected as the explicit moisture scheme. The Grell cumulus parameterization was also selected, taking into account shallow cumulus processes. A cloud-radiation scheme was used to account for long- and short-wave radiative transfer. A 5-layer soil model was used as the land surface model. The US National Weather Service National Centers for Environmental Prediction (NCEP) $1^{\circ} \times 1^{\circ}$ reanalysis data (6-hourly) was used to provide lateral boundary conditions and initial conditions for the MM5 operations. The duration of simulation was from 5 July to 31 July, and the initial meteorological conditions were restarted every three days in the MM5 simulation exercises.

Detailed information about the emission inventory and CMAQ configuration is the same as with our previous studies [22]. The Meteorology-Chemistry Interface Processor (MCIP) is a process interface that bridges MM5 and CMAQ. One function of MCIP is to transfer the meteorological output from MM5 model to the air quality model ready format. MCIP module has considered a series of atmospheric physic processes and dynamic algorithms and has capability of estimating the boundary layer parameters, cloud diagnosis, and dry deposition velocities of each chemical species.

\section{Results and Discussions}

4.1. Numerical Simulation Results. First, we compared the moving track and low sea surface pressure center of typhoon Haitang between MM5 simulation results and Best Track of Typhoon located by WMO (ftp://eclipse.ncdc.noaa.gov/pub/ ibtracs/v03r06/wmo/csv/year) during the episode days (figures not shown). It was found that the MM5 simulation results ideally reproduced the northwest-moving direction of typhoon Haitang and its intensity evolution. In general, the error of the moving track is smaller upon the ocean as compared to the time period of July 17 to July 19,2005 , than upon land on July 20,2005, with the average absolute error of typhoon locations between MM5 and Best Track being 

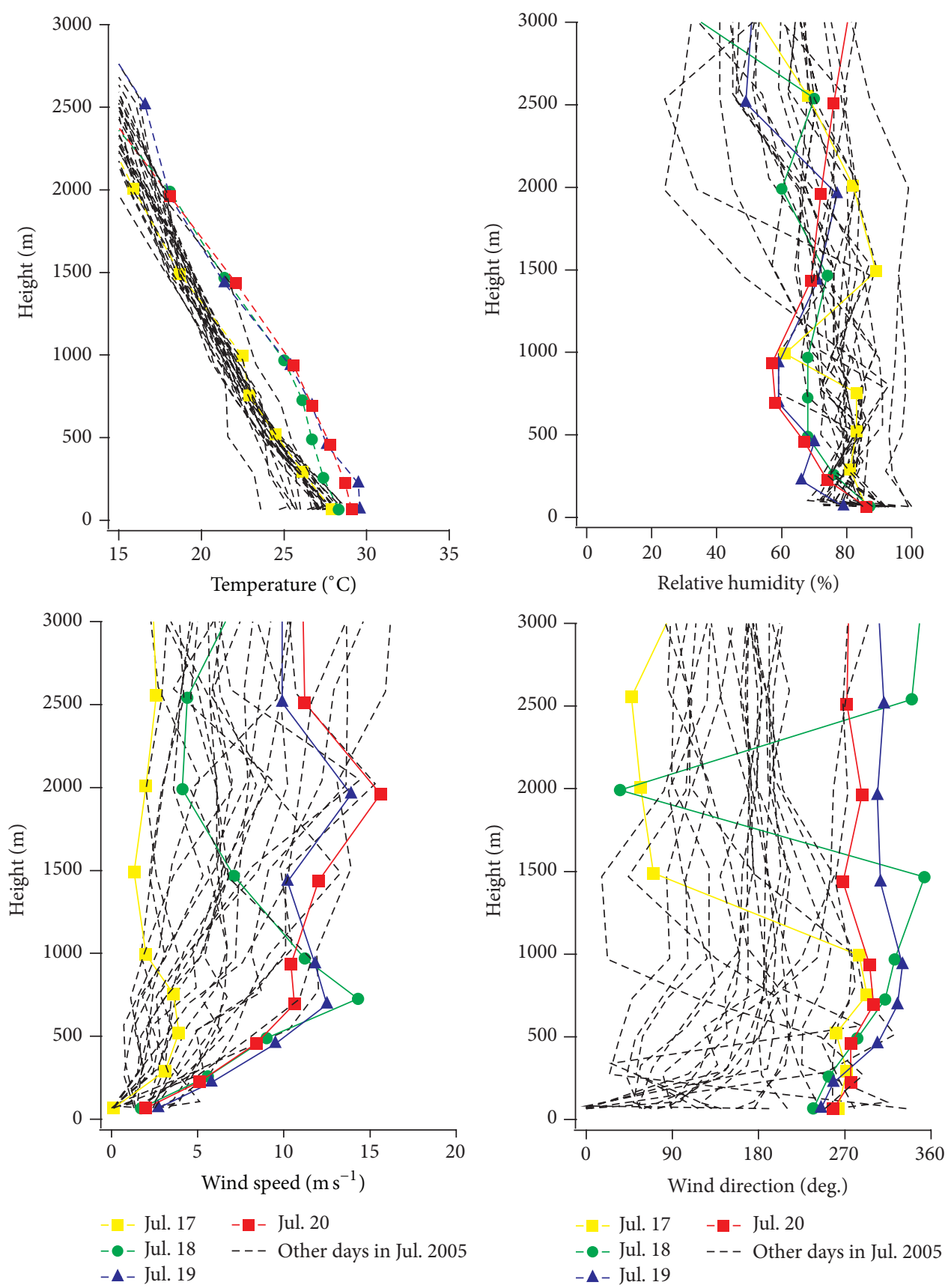

FIGURE 3: Observed vertical profiles of temperature, relative humidity, wind speed, and wind direction at 8:00 LST at KP station (solid lines represent days of 17 to 20 July 2005, dashed lines represent the other nonepisode days in July, and the last three days of data for July 2005 are omitted due to abnormal weather with heavy and squally showers.)

85 kilometers upon ocean, while enlarged to approximately 100 kilometers during the whole episode days. As to the sea surface pressure of the typhoon center, the deviation of MM5 and Best Track was as high as $58 \mathrm{hPa}$ at the beginning of Jul. 17, 2005, the deviation became significantly reduced with typhoon moving close to South China, and the average error is $18 \mathrm{hPa}$ during the whole episode days, which is definitely acceptable simulation results.

The most crucial factor that controls the formation of photochemical smog is meteorology, so it is important to ensure the quality of the meteorological simulations. Since the aim of this study was to focus on the dynamics of typhoon Haitang, the performance evaluation of the MM5 model was done by comparing the observed hourly relative humidity, air temperature at $2 \mathrm{~m}$, wind speed, and wind direction against concurrent simulation results. Figure 5 shows that the model reproduced the lower relative humidity and higher air temperature during the ozone episode days as compared to the nonepisode days. The Mean Absolute Error (MAE) of relative humidity and air temperature between 

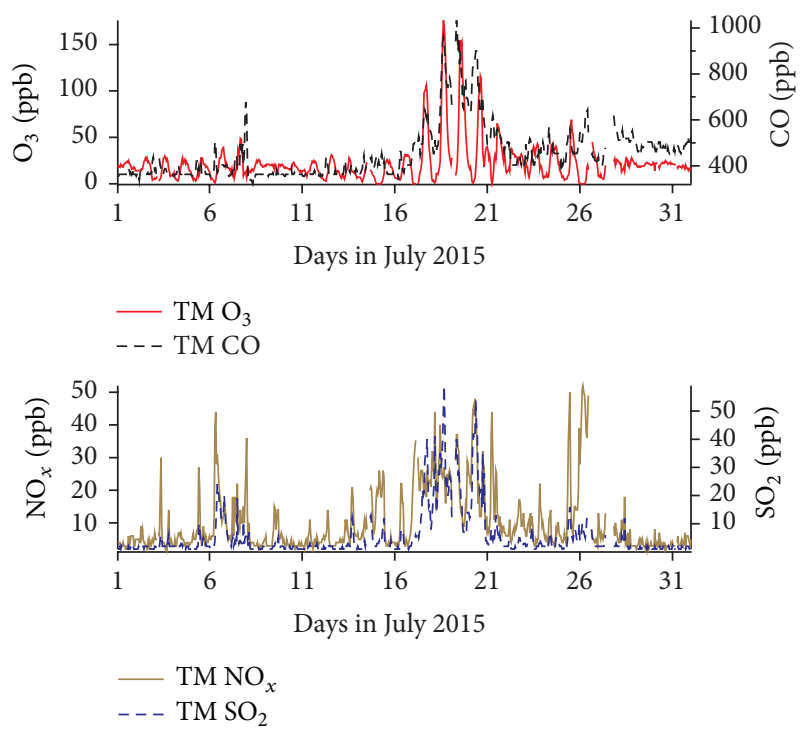

FIgURE 4: Concentration of $\mathrm{O}_{3}, \mathrm{CO}, \mathrm{NO}_{x}$, and $\mathrm{SO}_{2}$ observed at TM station.

model and observation was approximately $6 \%$ and 1 degree Celsius, respectively. The model tended to overestimate wind speed at the HKO station, which was generally a common phenomenon in modeling rough coastal regions; the MAE of wind speed was as high as $4 \mathrm{~m} \mathrm{~s}^{-1}$ in this case as calculated. The simulation results showed a relative increase of wind speed during the ozone episode from 17 July to 20 July. As to the wind direction, the similarity between the model and observed wind direction was remarkable.

In Hong Kong, many stations monitor either air quality or meteorology; however, none are designed to observe both air quality and meteorology at the same site. Thus, air quality evaluation is carried out at a downwind TM station.

Figure 5 also shows the time series for both the simulated and observed $\mathrm{O}_{3}$ and $\mathrm{NO}_{x}$ at the TM station. It is worth noting that the model simulated $\mathrm{O}_{3}$ and $\mathrm{NO}_{x}$ concentrations reasonably tracked the occurrence of the episode between 17 July and 20 July. In general, the model overestimated the mean ozone concentration but underestimated the peak values during episode days. The persistent overestimated ozone concentration on the nonepisode days is most likely due to the initial conditions and boundary conditions of chemical components, the default ozone initial and boundary concentration were set to $35 \mathrm{ppb}$, and the horizontal distribution of the whole domain was uniform.

At the same time, the model slightly underestimated both the mean and peak values of $\mathrm{NO}_{x}$ concentrations. The simulation of $\mathrm{NO}_{x}$ is $20 \%$ to $50 \%$ lower than the observed $\mathrm{NO}_{x}$, which could be partly attributed to the coarse resolution of the $36 \mathrm{~km}$ grid size. Overall, the MAEs of $\mathrm{O}_{3}$ and $\mathrm{NO}_{x}$ between model and observation were 29 and $16 \mathrm{ppb}$ during this ozone episode and occurred between 17 July and 20 July. The formation and dissipation of the ozone episode were captured.
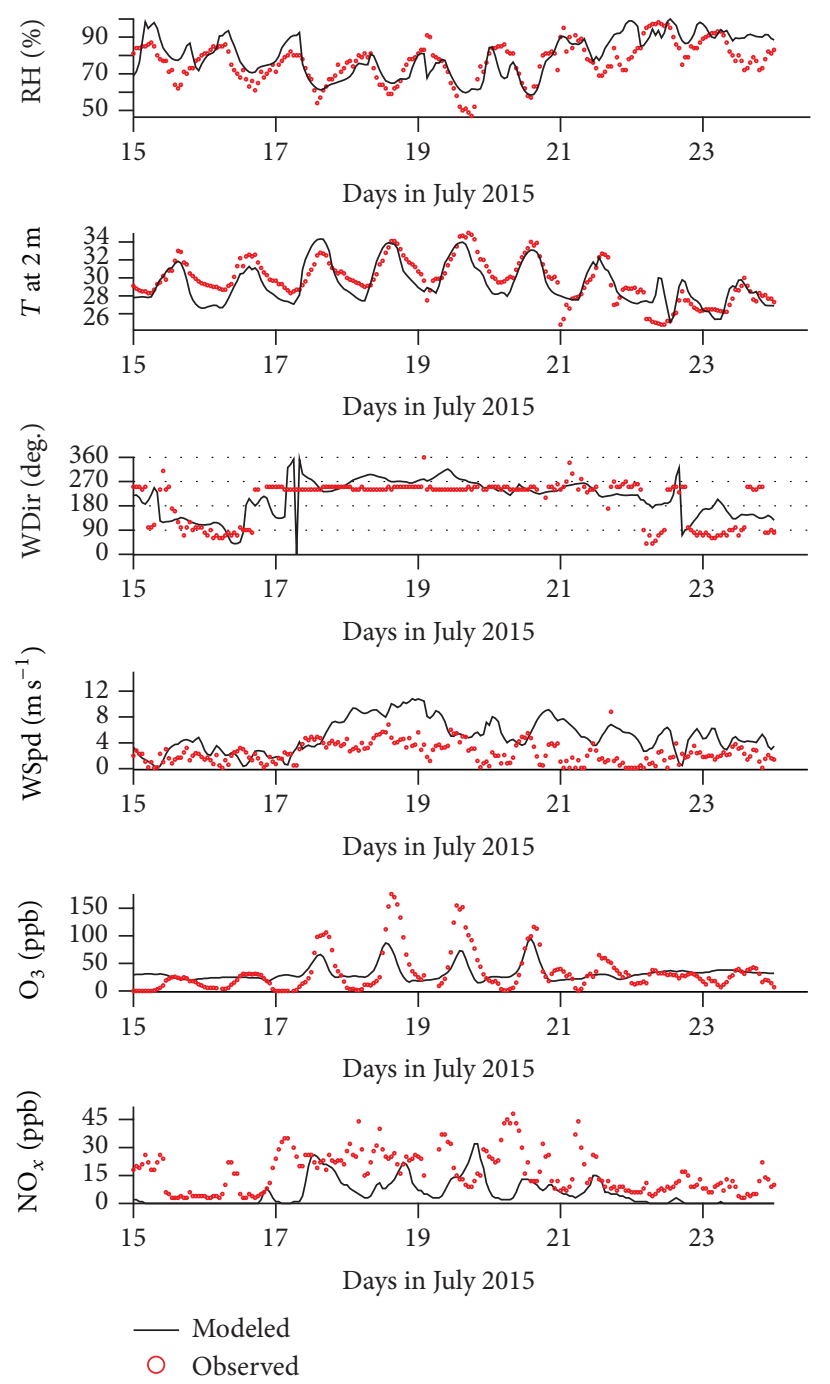

FIGURE 5: The modeled and observed relative humidity (RH, unit: $\%$ ), air temperature at 2 meters ( $T$ at $2 \mathrm{~m}$, unit: degrees Celsius), wind direction (WDir, unit: degree), and wind speed (WSpd, unit: $\mathrm{m} \mathrm{s}^{-1}$ ) at $\mathrm{HKO}$ station and the modeled and observed $\mathrm{O}_{3}$ and $\mathrm{NO}_{x}$ at TM station from top to bottom of the figure.

4.2. Synoptic Analysis. When Haitang was drawing close to Taiwan, the ground level wind flow in the PRD region was significantly influenced by its outer band circulation. The modeled horizontal 10-meter wind flow patterns at 14:00 on 17 to 20 July are shown in Figure 6. The cyclonic typhoon circulation largely dominated the wind flow in Hong Kong. The induced 10-meter wind flow in Hong Kong was mainly westerly with a moderate speed. Hong Kong is located on the eastern side of the PRD region. This kind of flow pattern with moderate wind speed was responsible for the horizontal advection of a large amount of primary air pollutants (emitted from the PRD region) to Hong Kong.

Figure 3 demonstrates significant differences between the wind speed and wind direction at ground level and at around 900 to 1000 meters. To further explore the possible wind shear of horizontal wind in low level, Figure 7 shows 

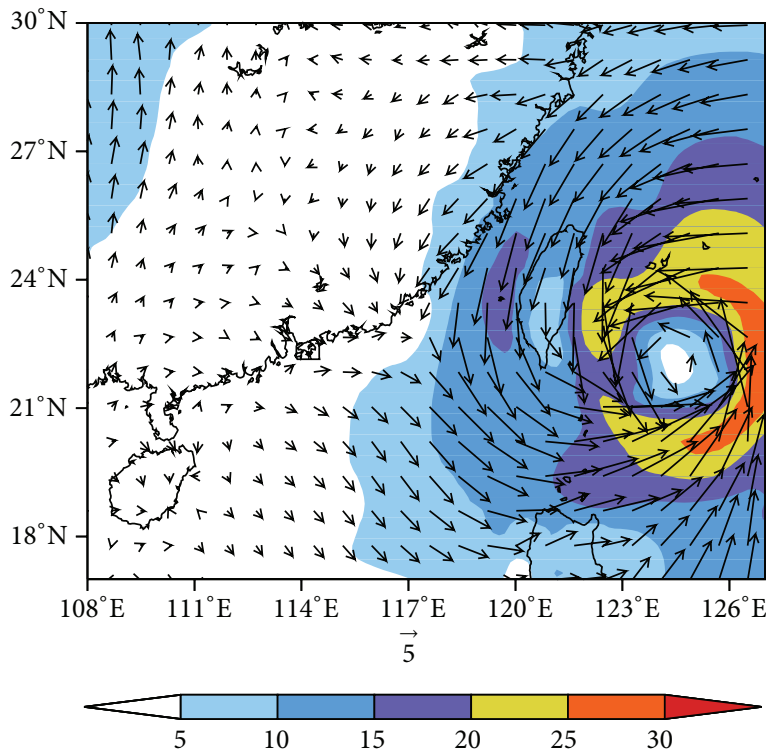

(a)
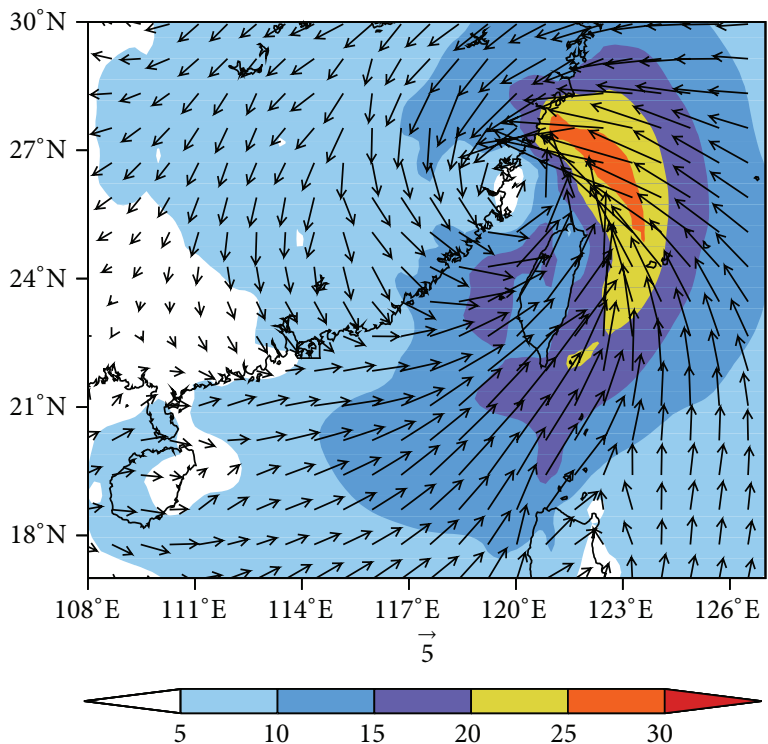

(c)
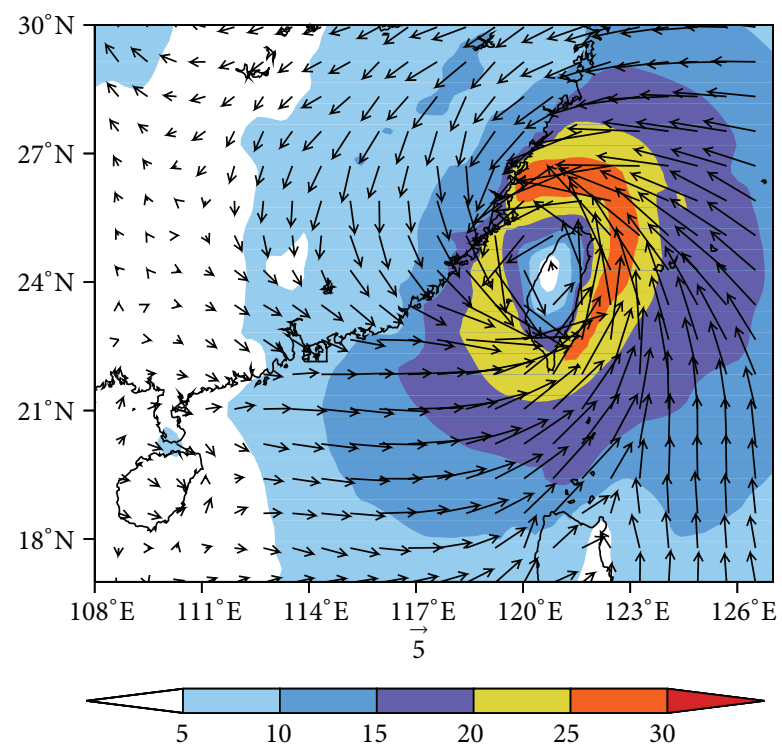

(b)
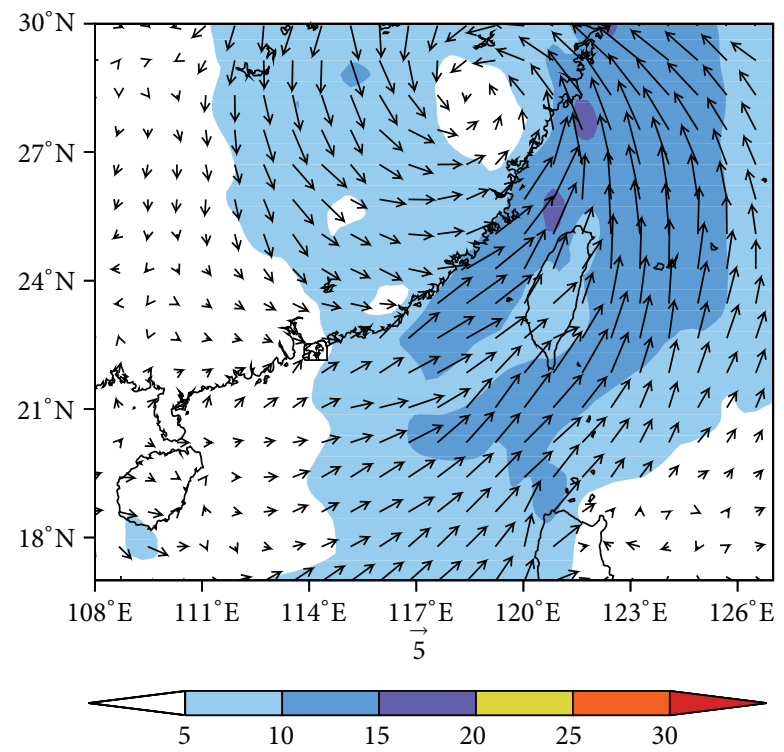

(d)

FIGURE 6: Model simulated 10-meter wind vectors (small arrows) and wind speed (unit: $\mathrm{m} \mathrm{s}^{-1}$, denoted as color shading areas) at 14:00 LST from (a) 17 to (d) 20 July 2005.

the temporal variation of the horizontal wind over the $\mathrm{HKO}$ station. Figures $7(\mathrm{a})-7(\mathrm{~d})$ show the continuous time from 09:00 July 17 to 02:00 July 21, 2005, covering the ozone episode days from July 17 to July 20, 2005. One can find that, in the upper level (above 1000 meters), the horizontal wind direction changed gradually counterclockwise from northerly wind to northwesterly. Between 18:00 and 03:00 during the midnight period of each daily episode, there was distinct development of southwesterly wind in the lower level under 1000 meters. The development of stronger wind shear in the vertical direction at nighttime might be due to the overlay of sea breeze effects at night.
To obtain more detail of the vertical wind shear, the meridional cross sections of $v$ and $w$ (vertical velocity) component streamline over HKO station at 18:00 on each of the four episode days are shown in Figure 8. The vertical wind velocity is also shown by shading (vertical velocity multiplied by 10 ). Figure 8 reveals the downward wind dominated most of the upper levels over Hong Kong (with latitude between $22 \mathrm{~N}$ and $22.5 \mathrm{~N}$ ). To some extent, this general pattern is influenced by a few local features, such as different land use type, different solar radiation level, and the differences between the land and sea. The confluence of northerly and southwesterly wind flow in Hong Kong from upper to lower 


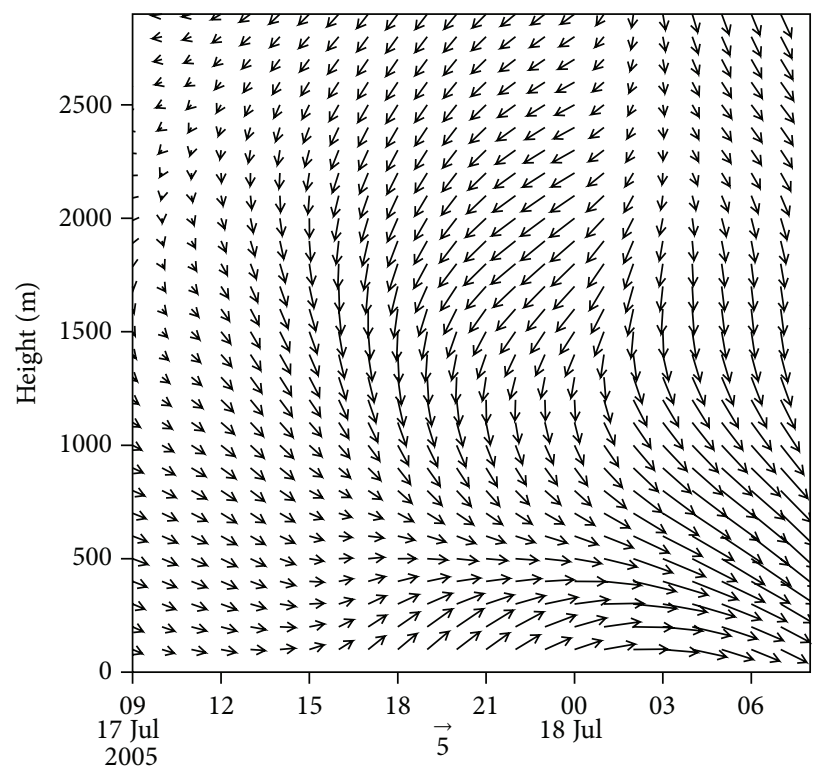

(a)

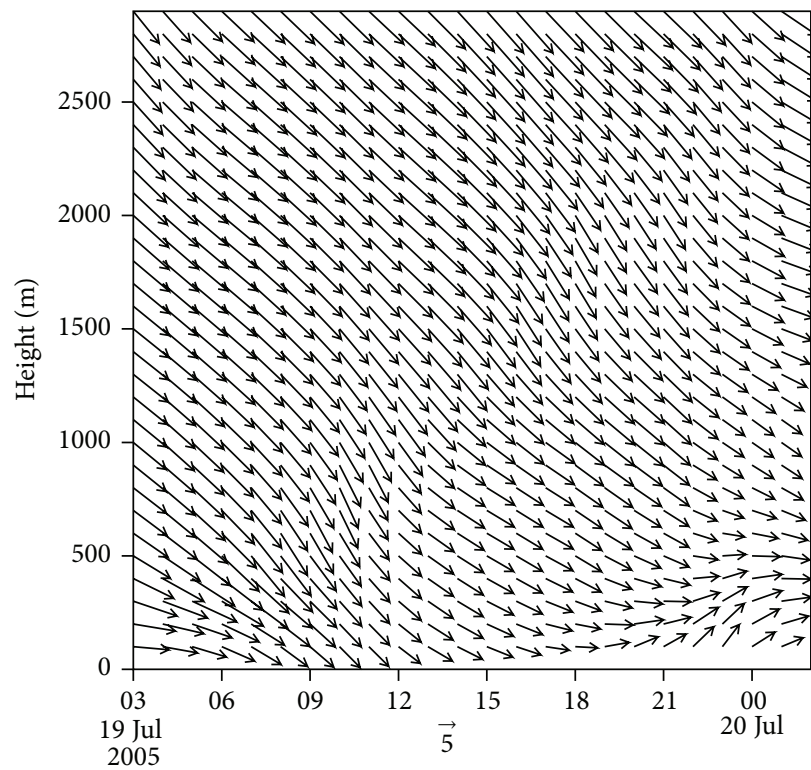

(c)

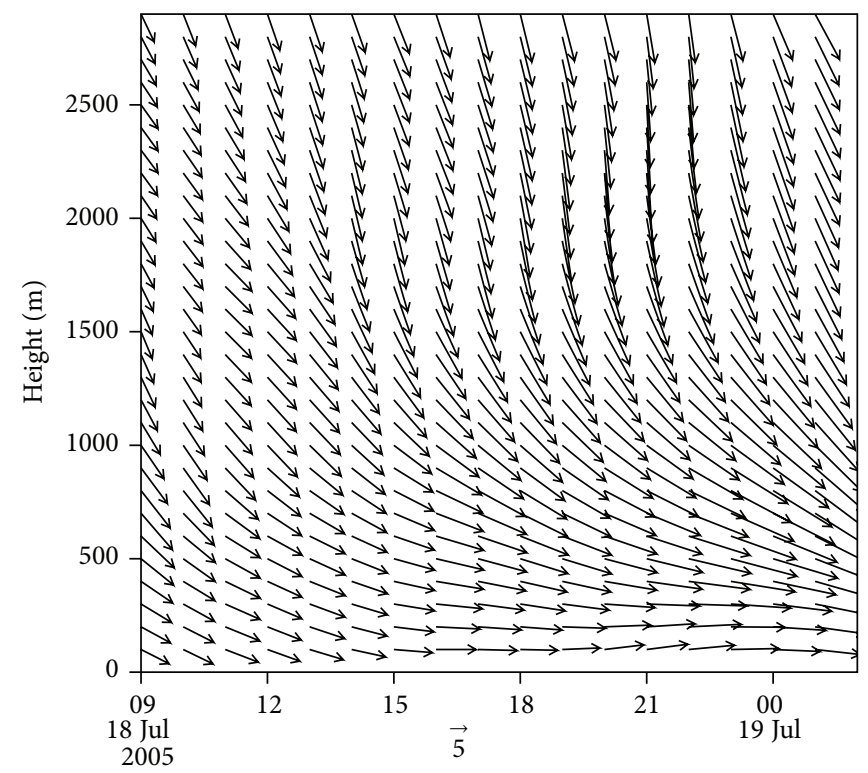

(b)

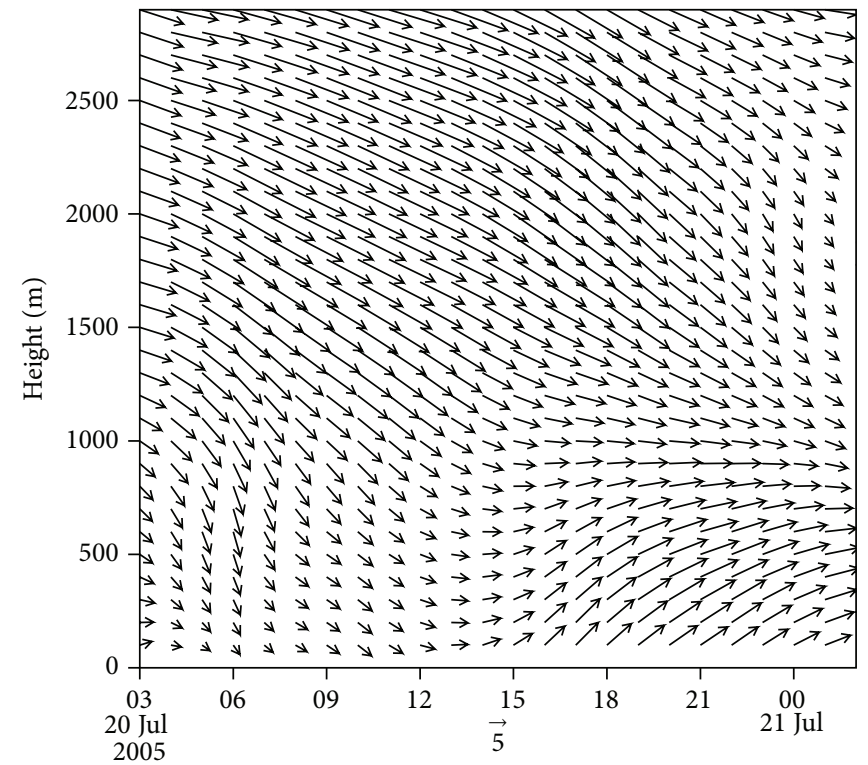

(d)

FIGURE 7: Temporal variation of modeled horizontal wind, the $y$-axis is height above ground, unit: meters. (a) shows the period from 09:00 Jul. 17 to 08:00 Jul. 18, 2005, (b) shows 09:00 Jul. 18 to 02:00 Jul. 19, 2005, (c) shows 03:00 Jul. 19 to 02:00 Jul. 20, 2005, and (d) shows 03:00 Jul. 20 to $02: 00$ Jul. $21,2005$.

level, combined with the downward draft in the south of Hong Kong, dramatically stimulated the development of a local vertical circulation. This local circulation occurred mainly around 18:00, continued to exist for a few hours, and then disappeared around midnight. This small scale circulation was associated with moderate wind speed. The primary air pollutants transported from the PRD region to Hong Kong at ground level by northwesterly wind were trapped by this local vertical circulation leading to accumulation of primary pollutants and formation of secondary pollutants.

According to the above analysis, the meteorological conditions contributing to the regional high ozone episode in Hong Kong under moderate wind speed are as follows: (a) the regional northwesterly wind flow in the PRD region was induced by typhoon Haitang, which favors the rapid transport of primary air pollutants from the PRD to Hong Kong area; (b) the horizontal confluence of wind flow combined with the downward draft aloft over the south part of Hong Kong and the development of the southwesterly wind in the low level after 18:00 stimulated a vertical local circulation at night, which trapped a large amount of air pollutants, while the rest of the pollutants continued heading south and dispersed into the sea; (c) on ground level, the hot air brought by the northerly wind and subsidence, together 


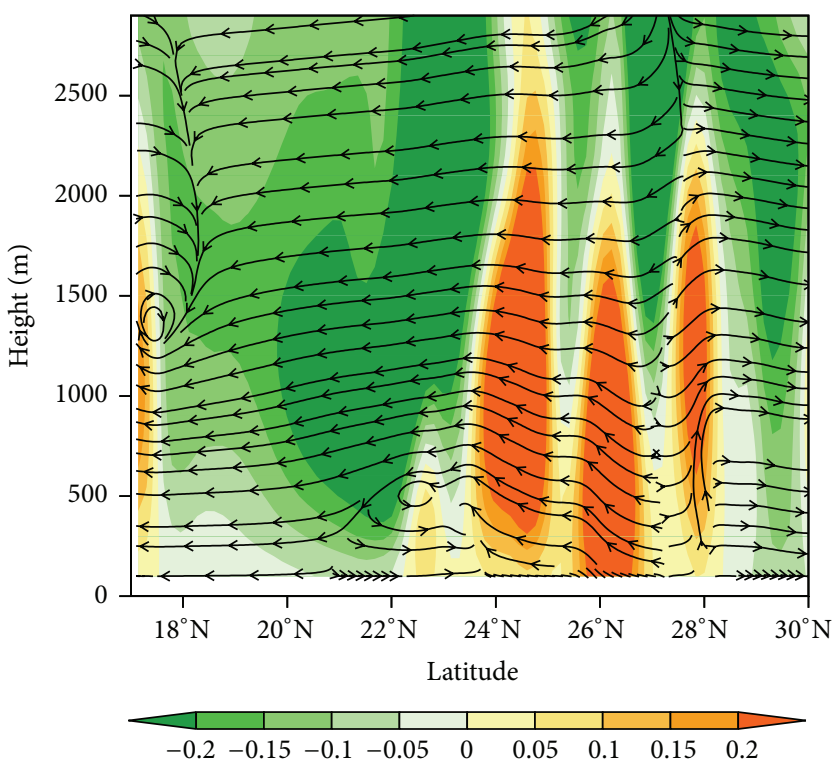

(a)

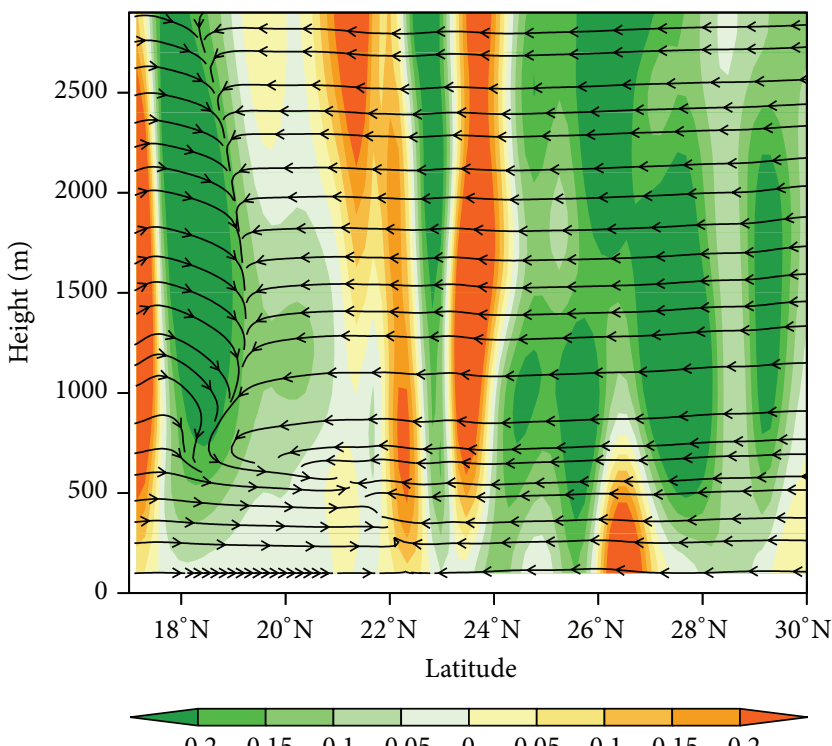

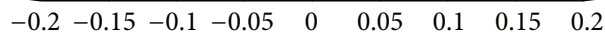

(c)

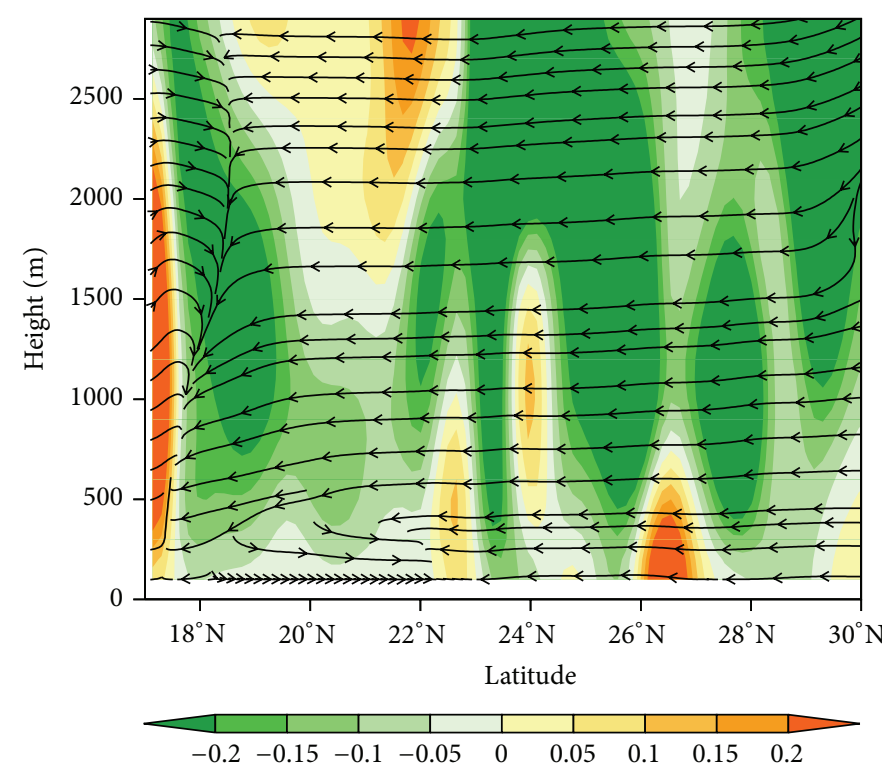

(b)

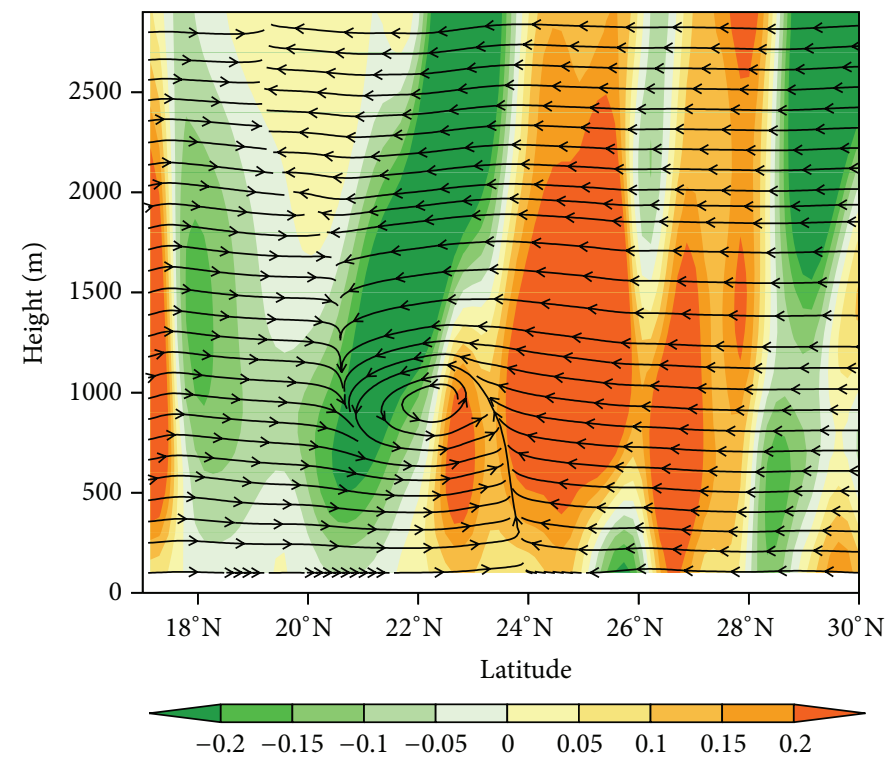

(d)

FIGURE 8: Vertical cross section of $v$ wind (unit: $\mathrm{m} \mathrm{s}^{-1}$ ) and $w$ (vertical velocity, unit: $0.1 \mathrm{~m} \mathrm{~s}^{-1}$ ) component streamline. Shadowed areas denote downward motion. The $y$-axis is height above ground, unit: meters. $22 \mathrm{~N}$ to $22.5 \mathrm{~N}$ is generally the location of Hong Kong. (a) At 18:00 July 17, 2005, (b) at 18:00 July 18, 2005, (c) at 18:00 July 19, 2005, and (d) at 18:00 July 20, 2005.

with the elevated temperature, favored the photochemical reaction over Hong Kong. This mechanism will be further discussed in the next section.

4.3. Process Analysis. Process analysis was carried out to study the ozone budget during the episode. The diagnostic tool integrated process rate analysis (IPRA) was used to apportion the contribution of different physical and chemical processes to the surface ozone concentration. This analysis can quantitatively assess all individual physics and the net effect of chemistry on the formation of $\mathrm{O}_{3}$ as well as other chemical species. The processes analyzed include horizontal advection and diffusion (the sum is called horizontal transport), vertical diffusion and transport (the sum is called vertical transport), chemical reactions, emissions, dry and wet deposition, and cloud process, which includes aqueous chemistry, scavenging, and cloud vertical mixing. Figure 9 shows the five main processes dominating the formation of ozone during the entire period of simulation at the ground level.

Comparing ozone budget of the four episode days of 17 July to 20 July with other nonepisode days in July 2005, the photochemical production was found to contribute greatest 


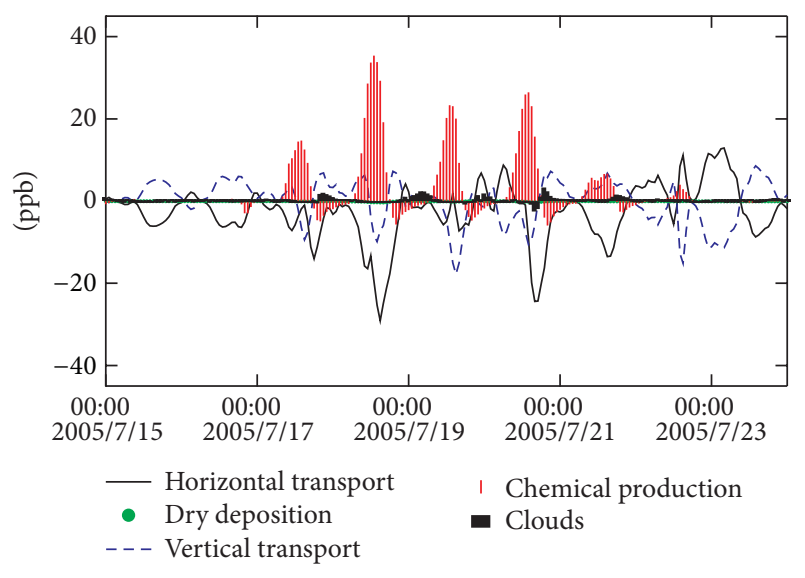

FIgURE 9: Process analysis of ozone budget from July 15 to July 24, 2005, at the ground level (from bottom to top).

to the high ozone concentration among all the physical and chemical processes, particularly at ground level. It is noticeable that the horizontal transport has very good negative correlation with the vertical transport on nonepisode days in July, whereas when the high ozone episode occurred, the anticorrelation was much weaker, which also suggests the contribution of ozone from the dynamic processes.

Linear regression was carried out to study the correlation between horizontal transport and vertical transport on both episode days and nonepisode days. The correlation coefficient on episode days is 0.0107 with $R$ square 0.0002 , whereas the correlation coefficient on nonepisode days is -0.9057 . This contrast indicates that, on nonepisode days, vertical transport usually cancels horizontal transport; thus, transport processes contribute very little to the net increase of ozone.

Overall, the meteorological mechanism of this episode was the coupling of wind transport with recirculating flow. Near the surface, Hong Kong was located in the convergent area of a synoptic flow with general subsidence motion. Moderate northwesterly and westerly winds over the PRD steered by the outer band flow of a typhoon converge coupled with broad subsiding air developed a recirculating flow on the southern part of the PRD region. Westerly wind lasted 4 days. Hong Kong is continuously downwind of the PRD industrial and urban areas. Although wind speed was higher than nonepisode days, the recirculating region trapped considerable primary air pollutants. Subsidence motion and the westerly winds brought hot air mass and abundant sunlight to Hong Kong. Under good sunlight, high temperature, and low relative humidity, excessive ozone was produced and accumulated; thus, the photochemical reactions were very active during the episode.

4.4. Air Mass Origin. High surface ozone could be caused by intrusion of stratospheric ozone [23] or long range transport of high ozone-rich air mass [24]. Ratio of chemical species can shed some light on origin of air mass. The scatter plots of observed $\mathrm{CO}$ and $\mathrm{O}_{3}$ in TW and TC station are shown in Figure 10, which clearly shows that CO concentration is poorly correlated with surface $\mathrm{O}_{3}$ concentration on nonepisode days. However, on the episode days, $\mathrm{CO}$ has good positive correlation with $\mathrm{O}_{3}$. This finding eliminates the possibility of stratospheric intrusion because air mass that has a stratospheric origin should be low in $\mathrm{CO}$ and high in $\mathrm{O}_{3}$. The good positive correlation indicates that air mass was associated with fresh pollutants.

\section{Discussions and Conclusions}

Using an integrated modeling system, that is, Models3/CMAQ, the formation mechanism of a high ozone episode that occurred in Hong Kong was examined. Simulation results provide a deeper understanding of the dynamics that contributed to photochemical smog. Haitang features moderate wind speed and nonstagnant air conditions, which was quite different from the light wind speed and stagnant meteorology condition in previous episodes studied. The dynamics can be summarized into three physical factors. First, the circulation at the outer band of Haitang induced north to west winds in South China. Westerly wind put Hong Kong directly downwind of the PRD emissions. Second, near the surface, a convergence of north wind and west wind, combined with the down draft driven by typhoon Haitang, created a wind shear stimulating vertical local circulation near the top of boundary layer, about 1000 to 1200 meters in this case. This recirculation trapped primary air pollutants and also allowed secondary pollutants to accumulate. Third, the conditions of high air temperature, low humidity, and bright sunshine (associated with subsiding air) allowed active photochemical reaction. All these factors combined to result in the formation of this high ozone episode.

It is interesting to discuss the comparison between typhoon Haitang and other typhoon related ozone episodes in previous studies. When comparing the moving track of typhoon Haitang and the severe tropical storm Melor studied in Feng et al. [17] (whose tracks can be found at http://www.weather.gov.hk/publica/tc/tc2005/english/ track0505.htm and http://www.weather.gov.hk/publica/tc/ tc2003/english/track0319.htm, resp.), Melor moved in a clockwise direction, while Haitang moved counterclockwise. Since Melor was farther, the peripheral downward flow and inversion layer were induced by subsidence warming, with local light wind as the dominant mechanism. Haitang was closer in distance; thus, the horizontal versus downward flow was equally important, and the convergence of flow from different directions resulted in a different formation mechanism of the ozone episode. These results need further study and statistical analysis.

\section{Conflict of Interests}

The authors declare that there is no conflict of interests regarding the publication of this paper.

\section{Acknowledgments}

The authors would like to express their gratitude to the Hong Kong Environmental Protection Agency and Hong Kong 


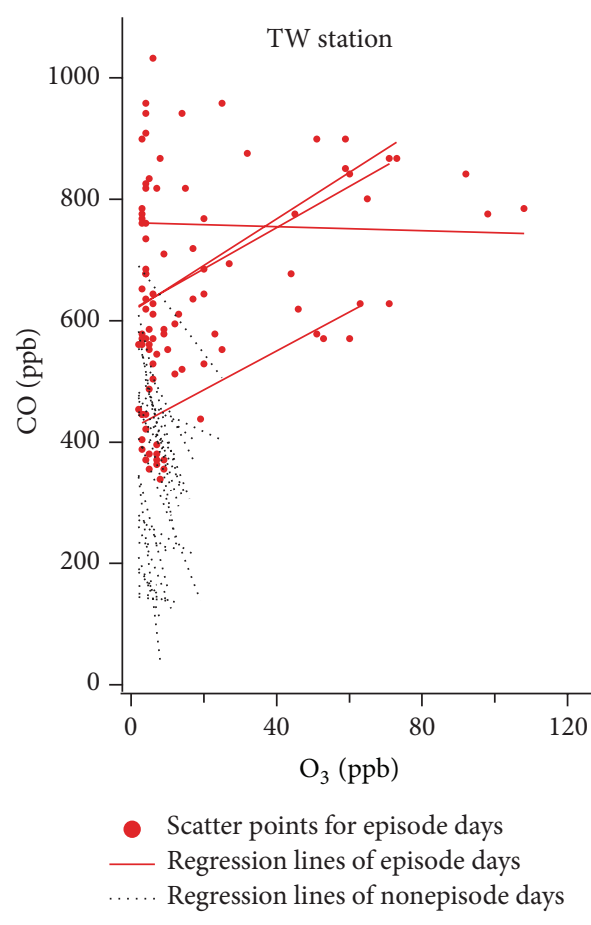

(a)

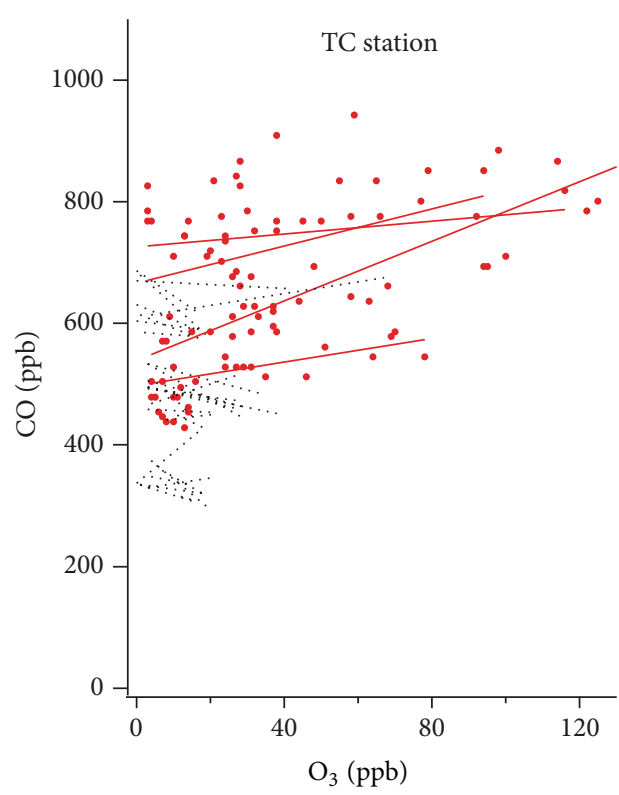

- Scatter points for episode days Regression lines of episode days Regression lines of nonepisode days

(b)

FIgURE 10: Scatter plots of CO versus $\mathrm{O}_{3}$ observed in TW (a) and TC (b) station of Hong Kong and their linear regression lines. Scatter points represent data of episode days, solid line represents regression line of episode days, while the dashed line represents nonepisode days. Scatter points for nonepisode days are not shown.

observatory for providing meteorological and air pollutant data. These data have greatly facilitated their research work. This project is supported by the Science and Technology Development project of the Regional Meteorological Center in South China (GRMC2012M16) and Science and Technology Research and Development project of Shenzhen (ZDSYS20140715153957030, JCYJ20120618114014134) and also by Hong Kong Polytechnic University, Central Research Grants (G-YN94).

\section{References}

[1] L. Y. Chan, C. Y. Chan, and Y. Qin, "Surface ozone pattern in Hong Kong," Journal of Applied Meteorology, vol. 37, no. 10, pp. 1153-1165, 1998.

[2] U. Dayan and I. Levy, "Relationship between synoptic-scale atmospheric circulation and ozone concentrations over Israel," Journal of Geophysical Research-Atmospheres D, vol. 107, no. 24, pp. 4813-4810, 2002.

[3] J. C. H. Fung, A. K. H. Lau, J. S. L. Lam, and Z. Yuan, "Observational and modeling analysis of a severe air pollution episode in western Hong Kong," Journal of Geophysical Research-Atmospheres D, vol. 110, no. 9, 2005.

[4] C. Y. Chan and L. Y. Chan, "Effect of meteorology and air pollutant transport on ozone episodes at a subtropical coastal Asian city, Hong Kong," Journal of Geophysical Research: Atmospheres, vol. 105, no. 16, Article ID 2000JD900140, pp. 20707-20724, 2000.

[5] T. J. Wang, K. S. Lam, M. Xie, X. M. Wang, G. Carmichael, and Y. S. Li, "Integrated studies of a photochemical smog episode in Hong Kong and regional transport in the Pearl River Delta of China," Tellus-Series B: Chemical and Physical Meteorology, vol. 58, no. 1, pp. 31-40, 2006.

[6] Y. C. Lee, G. Calori, P. Hills, and G. R. Carmichael, "Ozone episodes in urban Hong Kong 1994-1999," Atmospheric Environment, vol. 36, no. 12, pp. 1957-1968, 2002.

[7] T. Wang and J. Y. H. Kwok, "Measurement and analysis of a multiday photochemical smog episode in the Pearl River Delta of China," Journal of Applied Meteorology, vol. 42, no. 3, pp. 404416, 2003.

[8] J. P. Huang, J. C. H. Fung, A. K. H. Lau, and Y. Qin, "Numerical simulation and process analysis of typhoon-related ozone episodes in Hong Kong," Journal of Geophysical Research D: Atmospheres, vol. 110, no. 5, Article ID D05301, 2005.

[9] D. Wu, X. Tie, C. Li et al., "An extremely low visibility event over the Guangzhou region: a case study," Atmospheric Environment, vol. 39, no. 35, pp. 6568-6577, 2005.

[10] M. Y. Zhou, Z. Chen, H. M. Hsu, and L. S. Chen, "Preliminary analysis of the field experiment CLATEX: properties of atmospheric boundary layer in process of the Vongfong landfall," in Proceedings of the WMO International Workshop on Tropical Cyclone Landfall Processes, Macao, China, 2005.

[11] J. X. Yang, A. K. H. Lau, J. C. H. Fung, W. Zhou, and M. Wenig, "An air pollution episode and its formation mechanism during the tropical cyclone Nuri's landfall in a coastal city of south China," Atmospheric Environment, vol. 54, pp. 746-753, 2012.

[12] Y. C. Jiang, T. L. Zhao, J. Liu et al., "Why does surface ozone peak before a typhoon landing in southeast China?" Atmospheric Chemistry \& Physics Discussions, vol. 15, pp. 24623-24642, 2015. 
[13] T. Wang, K. S. Lam, A. S. Y. Lee, S. W. Pang, and W. S. Tsui, "Meteorological and chemical characteristics of the photochemical ozone episodes observed at Cape D'Aguilar in Hong Kong," Journal of Applied Meteorology, vol. 37, no. 10, pp. 1167-1178, 1998.

[14] X.-M. Hu and M. Xue, "Influence of Synoptic Sea Breeze Fronts on the Urban Heat Island Intensity in Dallas-Fort Worth, Texas," Monthly Weather Review, 2015.

[15] A. Ding, T. Wang, M. Zhao, T. Wang, and Z. Li, "Simulation of sea-land breezes and a discussion of their implications on the transport of air pollution during a multi-day ozone episode in the Pearl River Delta of China," Atmospheric Environment, vol. 38, no. 39, pp. 6737-6750, 2004.

[16] F. Lasry, I. Coll, and E. Buisson, "An insight into the formation of severe ozone episodes: modeling the 21/03/01 event in the ESCOMPTE region," Atmospheric Research, vol. 74, no. 1-4, pp. 191-215, 2005.

[17] Y. Feng, A. Wang, D. Wu, and X. Xu, "The influence of tropical cyclone Melor on PM10 concentrations during an aerosol episode over the Pearl River Delta region of China: numerical modeling versus observational analysis," Atmospheric Environment, vol. 41, no. 21, pp. 4349-4365, 2007.

[18] J. R. Arnold, R. L. Dennis, and G. S. Tonnesen, "Diagnostic evaluation of numerical air quality models with specialized ambient observations: testing the Community Multiscale Air Quality modeling system (CMAQ) at selected SOS 95 ground sites," Atmospheric Environment, vol. 37, no. 9-10, pp. 1185-1198, 2003.

[19] C. Hogrefe, B. Lynn, K. Civerolo et al., "Simulating changes in regional air pollution over the eastern United States due to changes in global and regional climate and emissions," Journal of Geophysical Research-Atmospheres, vol. 109, no. 22, Article ID D22301, pp. 2156-2202, 2004.

[20] S. Pressley, B. Lamb, H. Westberg, A. Guenther, J. Chen, and E. Allwine, "Monoterpene emissions from a Pacific Northwest Old-Growth Forest and impact on regional biogenic VOC emission estimates," Atmospheric Environment, vol. 38, no. 19, pp. 3089-3098, 2004.

[21] D. W. Byun and J. K. S. Ching, Science Algorithms of the EPA Models-3 Community Multiscale Air Quality (CMAQ) Modeling System, US Environmental Protection Agency, Washington, DC, USA, 1999.

[22] X. L. Wei, Q. Liu, K. S. Lam, and T. J. Wang, "Impact of precursor levels and global warming on peak ozone concentration in the Pearl River Delta Region of China," Advances in Atmospheric Sciences, vol. 29, no. 3, pp. 635-645, 2012.

[23] A. J. Ding and T. Wang, "Influence of stratosphere-totroposphere exchange on the seasonal cycle of surface ozone at Mount Waliguan in western China," Geophysical Research Letters, vol. 33, no. 3, Article ID L03803, 2006.

[24] H. Akimoto, H. Mukai, M. Nishikawa et al., "Long-range transport of ozone in the East Asian Pacific rim region," Journal of Geophysical Research: Atmospheres, vol. 101, no. 1, pp. 19992010, 1996. 

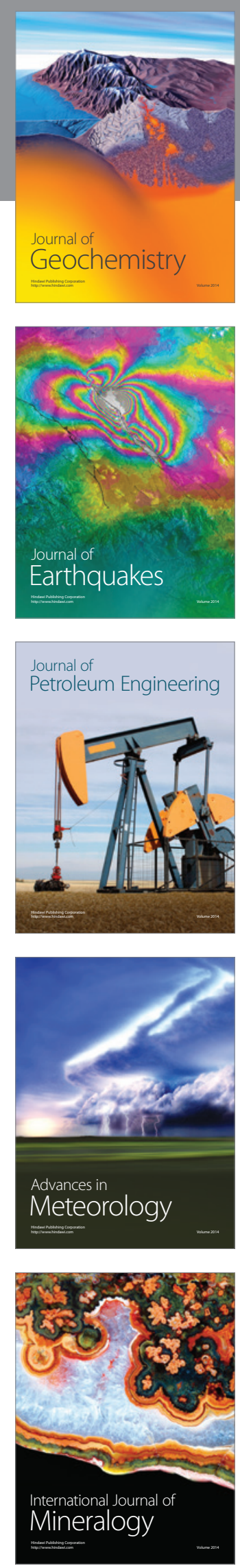
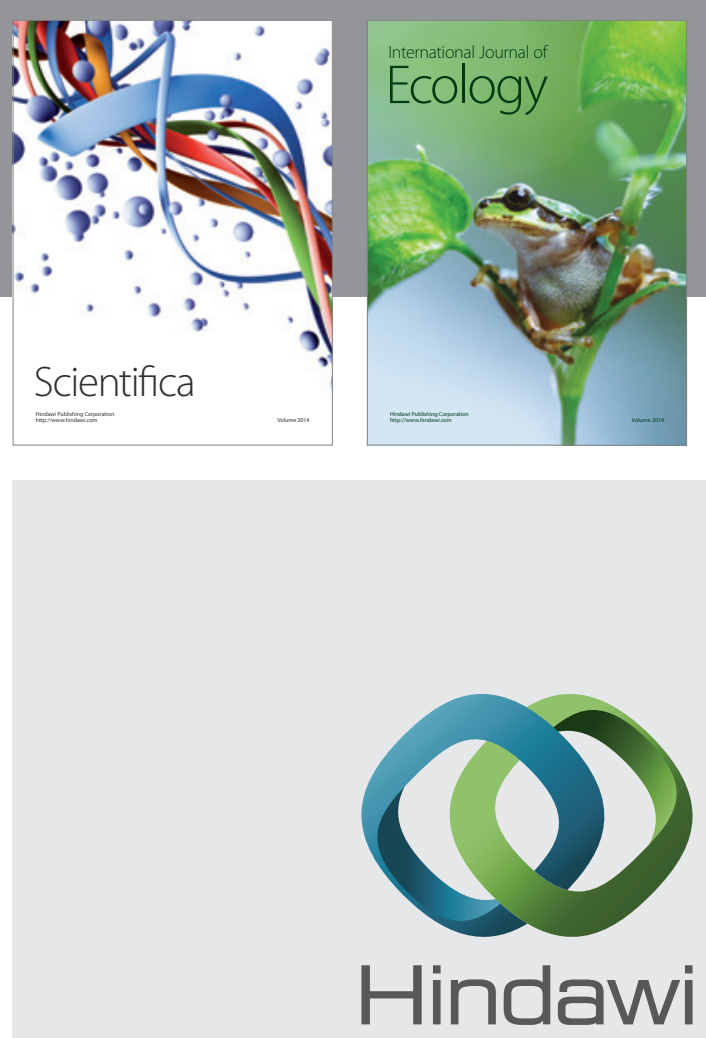

Submit your manuscripts at

http://www.hindawi.com
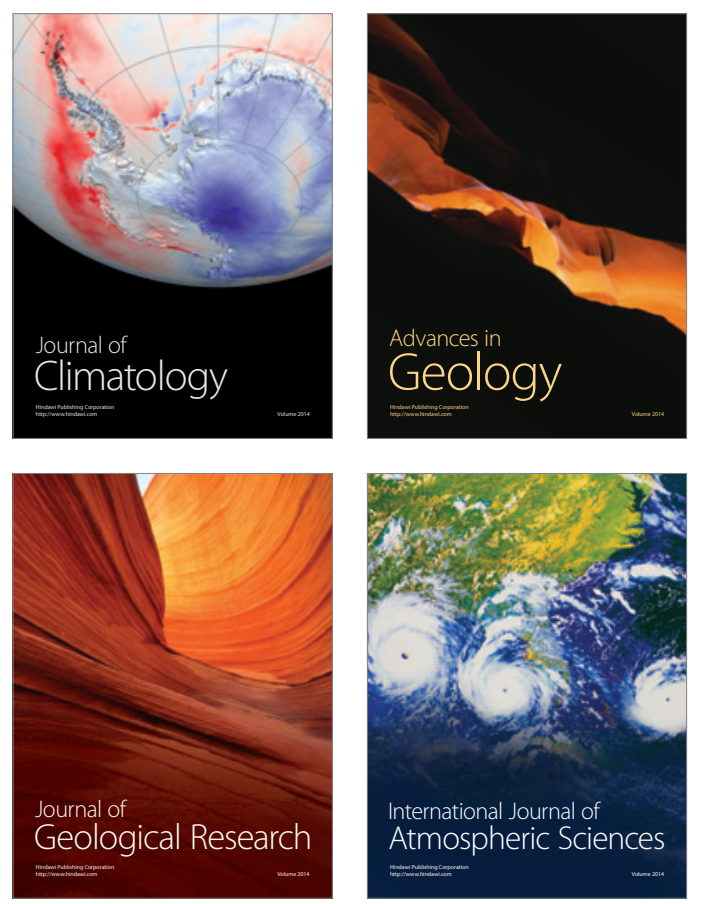

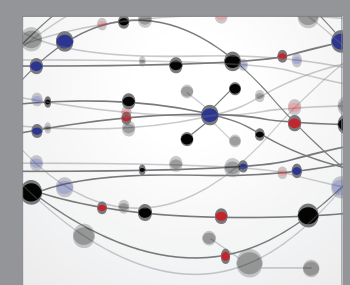

The Scientific

\section{World Journal}
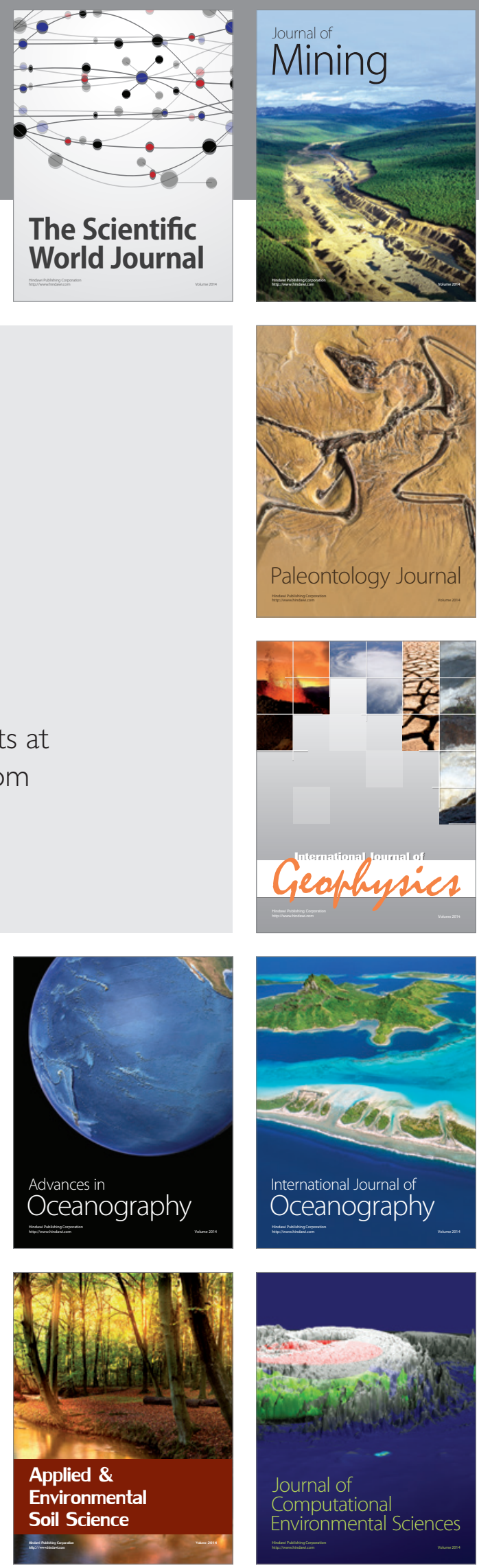